\title{
A PROSPECTIVE STUDY COMPARING TAMSULOSIN AND SILODOSIN IN MEDICAL EXPULSIVE THERAPY FOR LOWER URETERIC STONES
}

\author{
Sreedhar Reddy ${ }^{1}$, Prathvi' ${ }^{2}$, Mayank Kulshreshtha ${ }^{3}$, Padmakar Singh ${ }^{4}$
}

1 Professor and Head, Department of Urology, Raja Rajeshwari Medical College and Hospital, Bangalore. ${ }^{2}$ Assistant Professor, Department of Urology, Raja Rajeshwari Medical College and Hospital, Bangalore. ${ }^{3}$ Post Graduate, Department of Urology, Raja Rajeshwari Medical College and Hospital, Bangalore. ${ }^{4}$ Post Graduate, Department of Urology, Raja Rajeshwari Medical College and Hospital, Bangalore.

\begin{abstract}
The urinary stone disease is one of the most common afflictions of the modern society and it has been described since antiquity with the westernization of global culture. The efficacy of mini-invasive therapies, such as Extracorporeal Shock Wave Lithotripsy [ESWL] and ureteroscopy are not risk free, are problematic and are quite expensive. Recently, the use of watchful waiting approach has been extended by using Pharmacotherapy. This can reduce symptoms and facilitate stone expulsion.
\end{abstract}

\section{MATERIALS AND METHODS}

This prospective randomised study was conducted between September 2015 and May 2016 at Rajarajeshwari Medical College and Hospital, Bangalore. The cohort comprised 100 adult patients (54 men and 46 women) who presented with a symptomatic, unilateral, single, uncomplicated lower ureteric stone of $\leq 10 \mathrm{~mm}$. Patients were randomized into two equal groups, 50 (50\%) patients received a daily single dose of tamsulosin $0.4 \mathrm{mg}$ for 28 days and 50 (50\%) patients received a daily single dose of silodosin $8 \mathrm{mg}$ for 28 days. Both groups were compared in terms of patient's demographics, socioeconomic status, stone size and side, type of MET, stone expulsion rate, stone expulsion time, number of pain episodes, need for analgesics use and incidence of side effects. Subgroup analysis was performed according to stone size $\leq$ or $>5 \mathrm{~mm}$.

\section{RESULTS}

No significant differences among the two groups for patient's age, gender, stone side and stone size. Spontaneous stone expulsion rate within 28 days was observed in 44 (88\%) patients in the tamsulosin group and in 45 (90\%) patients in the silodosin group without statistically significant differences. There were no statistically significant differences observed in terms of mean expulsion time, mean number of pain episodes and need for analgesics. Retrograde ejaculation was significantly higher in the silodosin arm, while the incidence of side effects related to peripheral vasodilation were higher in the tamsulosin arm, but it was statistically insignificant.

\section{CONCLUSION}

Tamsulosin and silodosin are equally effective as MET for distal ureteric stones sized $10 \mathrm{~mm}$ or smaller. MET with silodosin is associated with a lower incidence of side effects related to peripheral vasodilation, but a higher incidence of retrograde ejaculation when compared to tamsulosin. However, a multicentre study on a larger scale is needed to evaluate the current medicines.

\section{KEYWORDS}

Tamsulosin, Silodosin, Stone Expulsion Rate, Medical Expulsion Therapy (MET).

HOW TO CITE THIS ARTICLE: Reddy S, Prathvi, Kulshreshtha M, et al. A prospective study comparing tamsulosin and silodosin in medical expulsive therapy for lower ureteric stones. J. Evolution Med. Dent. Sci. 2016;5(59):4108-4111, DOI: $10.14260 /$ jemds/2016/939

\section{INTRODUCTION}

The urinary stone disease is one of the most common afflictions of the modern society and it has been described since antiquity with the westernization of global culture, afflicting $13 \%$ of men and $7 \%$ of women.(1) The life-time risk of urinary stone disease is estimated to be between $5 \%$ and $12 \%$ in Europe and US among all urinary tract stones, 20\% present as ureteral stones of which $70 \%$ are found in the lower third of the ureter.(2) The efficacy of mini-invasive therapies, such as Extracorporeal Shock Wave Lithotripsy [ESWL] and ureteroscopy has been proven by several studies.(3)

Financial or Other, Competing Interest: None.

Submission 18-06-2016, Peer Review 13-07-2016,

Acceptance 18-07-2016, Published 25-07-2016.

Corresponding Author:

Dr. Sreedhar Reddy,

Professor and HOD,

Department of Urology

Raja Rajeshwari Medical College and Hospital,

Bangalore.

E-mail: urologyreddy@yahoo.com

DOI: $10.14260 /$ jemds/2016/939
Nevertheless these techniques are not risk free, are problematic and are quite expensive.(4) Recently, the use of watchful waiting approach has been extended by using Pharmacotherapy. This can reduce symptoms and facilitate stone expulsion.(5)

Both the AUA.(6) and the European Association of Urology (EAU).(7) recommend a-blockers for the treatment of ureteric stones. Recently, the $\alpha 1 \mathrm{~A}$-adrenoceptor subtype has been shown to play the major role in mediating phenylephrineinduced contraction of the human isolated ureter.(8) In the human ureter, silodosin (A selective $\alpha 1$-adrenoceptor blocker) was found to be more effective than an a1D-adrenoceptor blocker in noradrenaline-induced contraction. (9)

However, published data are limited on the use of silodosin as MET for DUS; thus we conducted a prospective randomized study to compare the efficacy and safety of silodosin vs tamsulosin as MET for single, symptomatic, uncomplicated lower ureteric stones in adults. 


\section{MATERIALS AND METHODS}

This prospective randomised study was conducted between September 2015 and May 2016 at Rajarajeshwari Medical College and Hospital, Bangalore. The cohort comprised 100 adult patients (54 men and 46 women) who presented with a symptomatic, unilateral, single, uncomplicated lower ureteric stone of $\leq 10 \mathrm{~mm}$.

\section{Inclusion Criteria}

1. Male or female patients, aged 20 and over.

2. Patients having ureteral calculi located in lower ureter on computerized tomography of kidney, ureter and bladder.

3. Patients whose calculi measures $10 \mathrm{~mm}$ and less.

4. Patients who voluntarily decide to take part in this study and give written consent.

\section{Exclusion Criteria}

1. Patients who did not give consent and were not willing to take part in the study.

2. Pregnant women or nursing mothers.

3. Patients with febrile UTI or severe hydronephrosis or ulcerative disease or hypotension.

4. Patients on $\alpha$-blockers or $\alpha / \beta$ blockers or CCB or steroid.

5. Patients whose urinary tracts are anatomically deformed or stenosed.

6. Patients who underwent invasive operation on their ureter before.

7. Patients whose blood creatinine levels are $1.4 \mathrm{mg} / \mathrm{dL}$ and over.

8. Single renal patients.

9. Pain resistant to conservative treatment (Non-tolerant patients).

10. Patients with NSAID drug intolerance or adverse effects of Tamsulosin/Silodosin during study.

11. Patient withdrew from the study at any time.

All patients were diagnosed by plain abdominal radiograph of the Kidneys, Ureters and Bladder (KUB), ultrasonography and non-enhanced spiral CT (in some cases). Every patient provided informed written consent after receiving information about the nature of the study, time to study end, adverse effects and the possibility of intervention if needed.

Patients were randomized into two equal groups, 50 $(50 \%)$ patients received a daily single dose of tamsulosin 0.4 $\mathrm{mg}$ for 28 days and $50(50 \%)$ patients received a daily single dose of silodosin $8 \mathrm{mg}$ for 28 days.

Both the groups of patients were strictly instructed to drink a minimum of $2 \mathrm{~L}$ of water daily and to use symptomatic treatment with injection of $75 \mathrm{mg}$ diclofenac on demand. All patients were advised to filter/strain their urine stream to detect stone passage and to stop the medications when the stone was expulsed and report for confirmation. Patients were followed up weekly with X-ray of the kidney, ureter and bladder region and with ultrasonography.

Data analysis was done using SPSS software. Our study protocol was approved by the Hospital Research and Ethics Committee and all patients provided an informed written consent for participation.

\section{RESULTS}

Data were recorded and compared in terms of patient's demographics, socio-economic status, stone size and side, type of MET, stone expulsion rate, stone expulsion time, number of pain episodes, need for analgesics use, incidence of side effects. Patients who experienced stone expulsion before first medication or who were lost to follow-up were excluded from the analysis. Subgroup analysis was performed according to stone size $\leq$ or $>5 \mathrm{~mm}$.

Any minimally invasive procedures like ureteroscopy, stenting, ESWL or discontinuation of MET during treatment period due to uncontrollable pain, adverse events, urinary tract infections, acute renal failure or the patient's decision for stone removal were considered failed therapy. Absence of stone expulsion after 28 days was considered failed therapy.

\begin{tabular}{|c|c|c|c|}
\hline & $\begin{array}{c}\text { Tamsulosin } \\
(n=50)\end{array}$ & $\begin{array}{c}\text { Silodosin } \\
(n=50)\end{array}$ & P value \\
\hline $\begin{array}{c}\text { Mean age in } \\
\text { years } \\
\text { (range) }\end{array}$ & $\begin{array}{c}39.4 \\
(21-70)\end{array}$ & $\begin{array}{c}38.2 \\
(21-70)\end{array}$ & n.s \\
\hline Gender M/F & $28 / 22$ & $26 / 24$ & n.s \\
\hline $\begin{array}{l}\text { Mean stone } \\
\text { size in mm } \\
\text { (range) } \\
\leq 5 \mathrm{~mm} \\
>5 \mathrm{~mm}\end{array}$ & $\begin{array}{l}28(56 \%) \\
22(44 \%)\end{array}$ & $\begin{array}{l}26(52 \%) \\
24(48 \%)\end{array}$ & $\begin{array}{l}\text { n.s } \\
\text { n.s }\end{array}$ \\
\hline $\begin{array}{c}\text { Ureteric } \\
\text { stone side } \\
\text { Left } \\
\text { Right }\end{array}$ & $\begin{array}{l}24(48 \%) \\
26(52 \%)\end{array}$ & $\begin{array}{l}27(54 \%) \\
23(46 \%)\end{array}$ & $\begin{array}{l}\text { n.s } \\
\text { n.s }\end{array}$ \\
\hline
\end{tabular}

There were no significant differences among the two groups for patient's age, gender, stone side and stone size.

Spontaneous stone expulsion rate within 28 days was observed in $44(88 \%)$ patients in the tamsulosin group and in $45(90 \%)$ patients in the silodosin group without statistically significant differences (Table 2). During the study period, hospitalization and ureteroscopy were required in 4 patients belonging to the tamsulosin arm and in 2 patients belonging to the silodosin arm.

There were no statistically significant differences observed in terms of mean expulsion time, mean number of pain episodes and need for analgesics. Retrograde ejaculation was significantly higher in the silodosin arm, while the incidence of side effects related to peripheral vasodilation (Dizziness, Postural hypotension, headache, nasal congestion) were higher in the tamsulosin arm, but it was statistically insignificant (Table 2). 


\begin{tabular}{|c|c|c|c|}
\hline & Tamsulosin (n=50) & Silodosin (n=50) & P value \\
\hline Expulsion rate (\%) & $44(88 \%)$ & $45(90 \%)$ & n.s \\
\hline $\begin{array}{c}\text { Stone expulsion time days } \\
\text { mean (range) }\end{array}$ & $6.4(3-14)$ & $7.2(3-14)$ & n.s \\
\hline Need for Analgesics & $1.0(0-3)$ & $1.0(0-3)$ & n.s \\
\hline Pain episodes mean (range) & $1.7(0-4)$ & $1.6(0-4)$ & $<0.05$ \\
Side effects & Nil & $5 / 26(19.2 \%)$ & n.s \\
Retrograde ejaculation & $5(10 \%)$ & $2(4 \%)$ & $n . s$ \\
Dizziness & $1(2 \%)$ & $2(4 \%)$ & n.s \\
Nasal congestion & $5(10 \%)$ & $2(4 \%)$ & n.s \\
Postural hypotension & $4(8 \%)$ & $2(4 \%)$ & \\
Headache & \multicolumn{2}{|c|}{ Table 2: Final Results } \\
\hline
\end{tabular}

Tamsulosin Silodosin

\begin{tabular}{|c|c|c|c|c|c|c|}
\hline & $\leq 5 \mathrm{~mm}$ & $>5 \mathrm{~mm}$ & P value & $\leq 5 \mathrm{~mm}$ & $>5 \mathrm{~mm}$ & P value \\
\hline $\begin{array}{l}\text { Expulsion } \\
\text { rate } \mathrm{n}(\%)\end{array}$ & $26 / 28(92.8 \%)$ & $18 / 22(81.8 \%)$ & n.s & $24 / 26(92.3 \%)$ & $21 / 24(87.5 \%)$ & n.s \\
\hline $\begin{array}{l}\text { Stone expulsion time } \\
\text { days mean (range) }\end{array}$ & $5.8(3-10)$ & $7.0(3-14)$ & $<0.05$ & $6.7(3-14)$ & $7.7(3-14)$ & $<0.05$ \\
\hline Pain episodes mean (range) & $1.5(0-3)$ & $2.6(0-5)$ & $<0.05$ & $1.3(0-3)$ & $2.2(0-4)$ & $<0.05$ \\
\hline Need for analgesics & $0.8(0-3)$ & $1.0(0-4)$ & n.s & $0.6(0-3)$ & $0.9(0-5)$ & n.s \\
\hline
\end{tabular}

On subgroup analysis, the mean expulsion times and the mean number of pain episodes were significantly lower in patients with smaller stones in both treatment arms (Table 3).

\section{DISCUSSION}

Ureteroscopy and SWL remain the most effective treatments for DUS; however, they are expensive and not risk free. Spontaneous stone expulsion can occur in up to $50 \%$ of cases; nevertheless, many complications such as ureteric colic, UTI and hydronephrosis may occur. Recently, the use of various adjuvant medications as MET for DUS has helped to reduce pain, complications and increase the rate of stone clearance.(10,11)

The $\alpha 1 \mathrm{~A}$ - and $\alpha 1 \mathrm{D}$-adrenoceptors are the most abundant subtypes in the distal ureter, stimulation of these a1 adrenoceptors leads to increases in both the frequency of ureteric peristalsis and the force of ureteric contractions. However, blockade of these receptors decreases basal ureteric tone, decreases peristaltic frequency and amplitude leading to a decrease in intraluminal pressure while the rate of urine transport increases and thus increasing the chance of stone passage.(12) Highly selective $\alpha 1 \mathrm{~A}$-adrenoceptor blockers have been developed to minimise the cardiovascular adverse effects while maintaining their efficacy on the urinary tract.(13)

Various trials demonstrated increased stone expulsion rates using tamsulosin, doxazosin, terazosin, alfuzosin and naftopidil.(14) Itoh performed the first prospective randomized study evaluating the use of silodosin in the management of ureteric stones $\leq 10 \mathrm{~mm}$. ${ }^{(15)}$ Tsuzaka compared the efficacy of the selective $\alpha 1 \mathrm{D}$ AR antagonist naftopidil and the selective $\alpha 1 \mathrm{~A}$ AR antagonist silodosin in the management of symptomatic $\leq 10 \mathrm{~mm}$ ureteral stones.(16) Vittorio Imperatore et al, compared for the first time tamsulosin and silodosin in the context of MET for distal ureteric stones.(17)

In patients presenting with DUS of $610 \mathrm{~mm}$ without the use of MET, the reported spontaneous stone clearance rates are between $35.2 \%$ and $61 \%$ with mean expulsion times ranging between 9.87 and 24.5 days.(18-21) Several factors can affect spontaneous stone clearance of DUS including: stone size, site, number and also the presence or absence of ureteric smooth muscle spasm and/or submucosal oedema. Coll et al found a direct relationship between stone size and spontaneous clearance.(22)

Results from our study, demonstrate stone expulsion rates and stone expulsion times in patients treated with tamsulosin that are within the published ranges. Patients treated with silodosin exhibit stone expulsion rates and mean expulsion times that are comparable to those reported in the tamsulosin group.

Most trials on MET for lower ureteric stones with tamsulosin demonstrated significant lower mean number of pain episodes with respect to placebo.(21-23) Results from the present study in terms of mean number of pain episodes and need for analgesics are within the published ranges for both the drugs.

In a study by $\mathrm{Yu} \mathrm{HG}$ et al, tamsulosin treatment resulted in a significant reduction in mean systolic blood pressure relative to the negligible change of silodosin.(24) The incidence of orthostatic hypotension with silodosin has been reported to be $<3 \%$. $(25)$

Results from our study shows retrograde ejaculation in 5 $(19.2 \%)$ patients treated with silodosin and none in tamsulosin group. The incidence of side effects related to peripheral vasodilation in tamsulosin group is 15 (30\%) and silodosin group is $8(16 \%)$, which is in accordance with most of the published studies. The lower incidence of side effects related to peripheral vasodilation associated with silodosin use make it more suitable for older patients.(26)

\section{CONCLUSION}

Tamsulosin and silodosin are equally effective as MET for distal ureteric stones sized $10 \mathrm{~mm}$ or smaller. MET with silodosin is associated with a lower incidence of side effects related to peripheral vasodilation, but a higher incidence of retrograde ejaculation when compared to tamsulosin. 
However, a multicentre study on a larger scale is needed to evaluate the current medicines.

\section{REFERENCES}

1. Hollingsworth JM, Rogers MA, Kaufman SR, et al. Medical therapy to facilitate urinary stone passage: a metaanalysis. Lancet 2006;368(9542):1171-9.

2. Wolf JS. Treatment selection and outcomes: ureteral calculi. Urol Clin North Am 2007;34(3):421-30.

3. Mille OF, Kane CJ. Time to stone passage for observed ureteral calculi: a guide for patient education. J Urol 1999;162(3 pt 1):688-90.

4. Lotan Y, Gettman MT, Roehroborn CG, et al. Management of ureteral calculi: a cost comparison and decision making analysis. J Urol 2002;167(4):1621-9.

5. Borghi L, Meschi T, Amat F, et al. Nifedipine and methylprednisolone in facilitating ureteral stone passage: a randomized, double blind, placebo-controlled study. J Urol 1994;152(4):1095-8.

6. Preminger GM, Tiselius HG, Assimos DG, et al. 2007 Guideline for the management of ureteral calculi. J Urol 2007;178(6):2418-34.

https://www.auanet.org/common/

pdf/education/clinical-guidance/Ureteral-Calculi.pdf.

7. Tiselius HG, Ackermann D, Alken P, et al. Guidelines on urolithiasis. Eur Urol 2001;40(4):362-71.

8. Sasaki S, Tomiyama Y, Kobayashi S, et al. Characterization of a1-adrenoceptor subtypes mediating contraction in human isolated ureters. Urology 2011;77(3):762, e13-7.

9. Kobayashi S, Tomiyama Y, Hoyano Y, et al. Gene expressions and mechanical functions of a1adrenoceptor subtypes in mouse ureter. World J Urol 2009;27(6):775-80.

10. Porpiglia F, Destefanis P, Fiori C, et al. Effectiveness of nifedipine and deflazacort in the management of distal ureter stones. Urology 2000;56(4):579-83.

11. Dellabella M, Milanese G, Muzzonigro G. Randomized trial of the efficacy of tamsulosin, nifedipine and phloroglucinol in medical expulsive therapy for distal ureteral calculi. J Urol 2005;174(1):167-72.

12. Griwan MS, Singh SK, Paul H, et al. The efficacy of tamsulosin in lower ureteral calculi. Urol Ann 2010; 2(2):63-6.

13. Rossi M, Roumegue're T. Silodosin in the treatment of benign prostatic hyperplasia. Drug Des Dev Ther 2010; 4:291-7.

14. Türk C, Knoll T, Petrik A, et al. Guidelines on urolithiasis. European Association of Urology Updated 2011.
15. Itoh Y, Okada A, Yasui T, et al. Efficacy of selective $1 \mathrm{~A}$ adrenoceptor antagonist silodosin in the medical expulsive therapy for ureteral stones. Int J Urol 2011; 18(9):672-4.

16. Tsuzaka $\mathrm{Y}$, Matsushima $\mathrm{H}$, Kaneko T, et al. Naftopidil vs silodosin in medical expulsive therapy for ureteral stones: a randomized controlled study in Japanese male patients. Int J Urol 2011;18(11):792-75.

17. Imperatore V, Fusco F, Creta $\mathrm{M}$, et al. Medical expulsive therapy for distal ureteric stones: tamsulosin versus silodosin. Archivio Italiano Urologia Andrologia 2014; 86(2):103-7.

18. Ahmed AF, Al-Sayed AY. Tamsulosin versus alfuzosin in the treatment of patients with distal ureteral stones: prospective, randomized, comparative study. Korean J Urol 2010;51(3):193-7.

19. Yilmaz E, Batislam E, Basar MM, et al. The comparison and efficacy of 3 different alpha1-adrenergic blockers for distal ureteral stones. J Urol 2005;173(6):2010-2.

20. Al-Ansari A, Al-Naimi A, Alobaidy A, et al. Efficacy of tamsulosin in the management of lower ureteral stones: a randomized double-blind placebo-controlled study of 100 patients. Urology 2010;75(1):4-7.

21. Agrawal M, Gupta M, Gupta A, et al. Prospective randomized trial comparing efficacy of alfuzosin and tamsulosin in management of lower ureteral stones. Urology 2009;73(4):706-9.

22. Coll DM, Varanelli MJ, Smith RC. Relationship of spontaneous passage of ureteral calculi to stone size and location as revealed by unenhanced helical CT. AJR Am J Roentgenol 2002;178(1):101-3.

23. Meguid ATA, Tayib A, Al-Sayyad A. Tamsulosin to treat uncomplicated distal ureteral calculi: a double blind randomized placebo-controlled trial. Can J Urol 2010; 17(3):5178-83.

24. Yu HJ, Lin AT, Yang SS, et al. Non-inferiority of silodosin to tamsulosin in treating patients with lower urinary tract symptoms (LUTS) associated with benign prostatic hyperplasia (BPH). BJU Int 2011;108(11):1843-8.

25. Schilit $S$, Benzeroual KE. Silodosin: a selective alpha1Aadrenergic receptor antagonist for the treatment of benign prostatic hyperplasia. Clin Ther 2009;31(11): 2489-502.

26. Chapple CR. A comparison of varying alpha-blockers and other pharmacotherapy options for lower urinary tract symptoms. Rev Urol 2005;7(Suppl 4):S22-30. 